\begin{tabular}{cc|c}
\hline Tar. Bil. Der. & Journal of Agricultural Sciences \\
& $\begin{array}{c}\text { Dergi web sayfası: } \\
\text { www.agri.ankara.edu.tr/dergi }\end{array}$ & Journal homepage: \\
& www.agri.ankara.edu.tr/journal
\end{tabular}

\title{
Dayanıklılık Geni Cre1'in Akdeniz Tahıl Kist Nematodu, Heterodera latipons Franklin (Tylenchida: Heteroderidae)'e Karşı Etkinliğinin Araştırılması
}

\author{
Mustafa İMREN ${ }^{a}$, Ece Börteçine KASAPOĞLU ${ }^{b}$, Abdelfattah DABABAT ${ }^{c}$, Halil TOKTAY ${ }^{d}$, İbrahim \\ Halil ELEKCIOĞLU ${ }^{b}$ \\ ${ }^{a}$ Abant İzet Baysal Üniversitesi, Ziraat ve Doğa Bilimleri Fakültesi, Bitki Koruma Bölümü, Bolu, TÜRKİYE \\ ${ }^{\boldsymbol{b}}$ Çukurova Üniversitesi, Ziraat Fakültesi, Bitki Koruma Bölümü, Adana, TÜRKIYYE \\ c International Maize and Wheat Improvement Centre (CIMMYT), Ankara, TÜRKIYYE \\ ${ }^{d}$ Niğde Üniversitesi, Tarım Bilimleri ve Teknolojileri Fakültesi, Bitkisel Üretim ve Teknolojileri Bölümü, Niğde, TÜRKIYE
}

\section{ESER BILGISI}

Araştırma Makalesi DOI: 10.1501/Tarimbil_0000001285

Sorumlu Yazar: Mustafa IMREN, E-posta: m.imren37@g-gmail.com, Tel: +90 (374) 2541000

Geliş Tarihi: 03 Aralık 2013, Düzeltmelerin Gelişi: 29 Ocak 2014, Kabul: 02 Mart 2014

\begin{abstract}
ÖZET
Tahıl kist nematodları (Heterodera avenae group) buğdayın önemli zararlılarından biri olup, Türkiye'de Heterodera avenae Wollenweber, H. latipons Franklin ve H. filipjevi (Madzhidov) Stone olmak üzere üç önemli türü farklı buğday üretim alanlarında saptanmıştır. Ülkemizin makarnalık buğdayın merkezi olan Güneydoğu Anadolu Bölgesi'nde Akdeniz tahıl kist nematodu, Heterodera latipons'un yaygın olarak bulunduğu, bölge genelinde birçok lokasyonda ekonomik zarar eşiğinin üstünde popülasyona sahip olduğu rapor edilmiştir. Buğday yetiștiriciliğinde kist nematodları ile en etkin mücadele yöntemi dayanıklı/tolerans çeşit kullanımı olarak bilinmektedir. Günümüzde buğdayın yabani türlerinden kültür formlarına aktarılmış dokuz farklı dayanıklılık geni (Cre genleri) mevcuttur. Bu çalışmada dayanıklılık geni Cre 1'in H. latipons'un Gaziantep (Karkamış) popülasyonuna karşı etkinliği araştırılmıştır. Çalışmada genomunda dayanıklılık geni Cre 1 bulunan SILVERSTAR buğday çeşidinin yanı sıra SOKOLL, CALINGIRI, GOLDMARKER, FRAME, STYLET, PASTOR ve CROC_1/AE.SQUARROSA(224)//OPATA çeşitlerine ait ebeveynlerin melezlenmesi ile geliştirilen 38 adeti dayanıklılık geni taşıyan, 26 adeti dayanıklılık geni taşımayan toplam 64 adet buğday genotipi H. latipons'a karşı denemeye alınmıştır. Çalışma sonucunda 64 adet genotipten 20'si nematoda dayanıklı, 32'si orta dayanıklı ve 12'sinin ise orta hassas olduğu tespit edilmiştir. Genomunda Cre 1 geni taşıan 38 melezden ise 10 'nun $H$. latipons'a karşı dayanıkl1, 20'sinin orta dayanıklı ve 8'nin ise orta hassas olduğu saptanmıştır. Bu çalışma ile dayanıklılık geni Cre1'in H. latipons'un Gaziantep (Karkamış) popülasyonuna karşı mutlak bir dayanıklılığa sahip olmamakla birlikte \%78 etkinlik oranı ile başarılı olduğu ve ulusal buğday 1slah programlarında $H$. latipons'a karşı kullanılabileceği sonucuna varılmıştır. Ayrıca, PASTOR, SOKOLL ve CROC_1/AE.SQUARROSA(224)//OPATA buğday genotiplerinin H. latipons'a karşı iyi bir dayanıklılık kaynağına sahip olduğu saptanmıştır.
\end{abstract}

Anahtar Kelimeler: Tahıl kist nematodu; Heterodera latipons; Buğday; Dayanıklılık

\section{Investigation the Efficiency of Resistance Gene, Cre1, Against Mediterranean Cereal Cyst Nematode: Heterodera latipons Franklin (Tylenchida: Heteroderidae)}

\author{
ARTICLE INFO \\ Research Article \\ Corresponding Author: Mustafa IMREN, E-mail: m.imren37@gmail.com, Tel: +90 (374) 2541000 \\ Received: 03 December 2013, Received in Revised Form: 29 January 2014, Accepted: 02 March 2014
}




\begin{abstract}
Cereal cyst nematodes (Heterodera avenae group) are important pests of wheat; they include the three most important species of cereal cyst nematodes: Heterodera avenae Wollenweber, H. latipons Franklin and H. filipjevi (Madzhidov) in Turkey that were determined in different wheat growing areas. It was reported that Mediterranean cereal cyst nematode, Heterodera latipons which is widely found in the centre of the durum wheat growing area -South-eastern Anatolia regionin our country was reaching the economical threshold in many locations. It is known that the use of resistant/tolerant wheat varieties is the most effective controlling method against cyst nematodes in the wheat cultivation. Nowadays, nine different resistance genes (Cre genes), which are transferred from wild wheat species to wheat cultivated forms are available. In this study, the efficiency of the resistance gene, Cre1, against the population of H. latipons from Gaziantep (Karkamıs) was investigated. In the study, 38 genotypes carrying $\mathrm{Cre} 1$ gene and 26 genomes lacking resistance genes; this gives a total 64 wheat genotypes which are produced by parental crossing of SILVERSTAR containing the resistance gene, Cre 1, in its genome, SOKOLL, CALINGIRI, GOLDMARKER, CROC_1/AE.SQUARROSA(224)//OPATA, FRAME, STYLET and PASTOR were used against H. latipons in the experiment. Among the 64 genotypes; 20 were resistant, 32 were moderately resistant and 12 were moderately susceptible to the nematode. Ten resistant, 20 moderately resistant and 8 moderately susceptible lines were determined against $H$. latipons that these 38 lines carried the Cre 1 gene in their genome. Within this study, the resistant gene, Cre1, was not found to be completely resistant against $H$. latipons, but its $78 \%$ efficiency rate was found to be successful: therefore, it was concluded that it can be used against $H$. latipons in national wheat breeding programs. Furthermore, PASTOR, SOKOLL and CROC_1/AE.SQUARROSA(224)//OPATA wheat genotypes were determined as good resistance source against $H$. latipons.
\end{abstract}

Keywords: Cereal cyst nematode; Heterodera latipons; Wheat; Resistance

(C) Ankara Üniversitesi Ziraat Fakültesi

\section{Giriş}

Buğday insan beslenmesindeki önemi nedeniyle birçok ülke için stratejik ürün kabul edilmektedir. Türkiye 9.4 milyon hektar ekim alanı ve 19-21 milyon ton üretimi ile dünyada ilk 10 üretici ülke arasında yer almaktadır (TUIK 2012). Ayrica ülkemiz sahip olduğu agro - ekolojik özelliklerin yanı sıra buğdayın gen merkezi olması nedeniyle buğday yetiştiriciliği ve 1slahı konusunda büyük bir potansiyele sahiptir.

Buğdayda birçok biyotik ve abiyotik etmen üründe kayıplara neden olmaktadır. Biyotik etmenler içerisinde bitki paraziti nematodlar buğdayda \%710 oranında ürün kaybına neden olmaktadır (Sasser 1987). Buğdayda zararlı nematodlar içerisinde; bitki kökünde kist oluşturmaları ile karakterize edilen tahil kist nematodu (Heterodera avenea group) ana zararlı konumundadır (Nicol et al 2002a). Tahıl kist nematodunun buğdayda beslenip çoğalan 12 türü mevcut olup, bunlardan Heterodera avenae Wollenweber, H. filipjevi (Madzhidov) Stelter ve $H$. latipons Franklin en önemlileri olarak bilinmektedir
(Rivoal \& Cook 1993; Nicol 2002b). Ülkemizde tahıl kist nematodunun söz konusu üç türü de saptanmış olup, bölgelere göre türlerin dağglımında farklılıklar olduğu bildirilmektedir (Rumpenhorst et al 1996; Subbotin et al 2003; Şahin 2010; İmren et al 2012; 2013). Tahil kist nematodu bitkide beslenmesi sonucu köklerde çatallanma, şişkinlik ile kütleşmeye bağlı olarak bitkinin gelişimini zayıflatmaktadır. Ayrıca, köklerin su besin alım düzeninin bozulması sonucu bitkide solgunluk ve bodurlaşmaya neden olduğu belirtilmektedir (Kort 1972; Agrios 1997).

Buğdayda zararlı nematodlara karşı en etkin mücadele yöntemi dayanıkl1/tolerant çeşit kullanımı olduğu bildirilmektedir (Schmidt et al 2005). Hastalık ve zararlılara dayanıklı gen kaynakları doğada çoğunlukla bitkilerin yabani formlarında mevcut olup melezleme çalışmaları ile kültür formlarına aktarılmıştır (Boerma \& Hussey 1992). Günümüzde buğdayın yabani formlarından buğdayda aktarılmış ve kist nematodlarına dayanıklılığı sağlayan genlerin (Cre genleri) olduğu bildirilmektedir (Barloy et al 2007). Cre genleri 
tek gen bölgesinden dayanıklılık sağlamakta olup, CreR, Cre1, Cre2, Cre3, Cre4, Cre5, Cre6, Cre7 ve $\mathrm{Cr} e 8$ olmak üzere dokuz adettir. $\mathrm{Cre}$ genlerinin etkinlikleri kist nematodunun türüne ve patotipine göre değişkenlik gösterebilmektedir (Majnik et al 2003). Örneğin, Cre3 geni H. avenae'nin Avrupa ve Afrika popülasyonlarına karşı oldukça etkili olurken, Avustralya ve Asya popülasyonlarına karşı etkili olmadığı bildirilmektedir (Rivoal et al 2001).

Tahıl kist nematodu konukçu genotiplerine virülensliği bakımından yüksek heterojeniteye sahip olduğu ve dünyada coğrafik bölgelere özelleşmiş farklı 13 patotipinin olduğu belirtilmektedir (Cook \& Rivoal 1998; Cook \& Noel 2002; Subbotin et al 2010). Bu nedenle, ulusal buğday islah programlarında kist nematoduna karşı dayanıklı hat ve çeşit geliştirilebilmesi için öncelikli olarak dayanıklılık genlerinin ülkemizdeki kist nematodu türlerine ve popülasyonlarına karşı etkinliklerinin araştırılması gerekmektedir. $\mathrm{Bu}$ çalışmada ülkemizde Güneydoğu Anadolu Bölgesi buğday alanlarında yaygın olarak bulunan kist nematodu, H. latipons'un Gaziantep ili Karkamış ilçesinde popülasyonuna karşı dayanıklılık geni Crel'in (Slootmaker et al 1974; Bekal et al 1988) etkinliğinin belirlenmesi amaçlanmıştır.

\section{Materyal ve Yöntem}

\subsection{Materyal}

Çalı̧̧mada, genomunda $\mathrm{Cr}$ 1 genine sahip ekmeklik buğday çeşidi SILVERSTAR (Majnik et al 2003)'ın da içinde olduğu SOKOLL, CALINGIRI, GOLDMARKER, FRAME, STYLET, PASTOR ve CROC_1/AE.SQUARROSA(224)//OPATA buğday çeşitlerine ait ebeveynlerin melezlenmesi ile geliştirilen 64 adet melez, kontrol hatları ve $H$. latipons'un Gaziantep (Karkamış) popülasyonu kullanılmıştır.

\subsection{Nematod inokulumun elde edilmesi}

Gaziantep ili Karkamış ilçesinde H. latipons ile bulaşık buğday tarlasından 2010 yılı buğday hasadı öncesinde yaklaşı $100 \mathrm{~kg}$ toprak ve kök örneği alınmış, çalışmada kullanılacak kistler toplanarak yüzey sterilizasyonları (Shepherd 1986) gerçekleştirilmiştir. Kistler önce $+5{ }^{\circ} \mathrm{C}$ de ardından $\mathrm{da}+10^{\circ} \mathrm{C}^{\prime}$ ye alınarak çalışma için gerekli nematod inokulumu elde edilmiştir (Scholz \& Sikora 2004).

\subsection{Denemelerin kurulması ve değerlendirilmesi}

Denemeye alınacak melezlere ait tohumların yüzey sterilizasyonu yapılıp çimlendirilmiş ve denemeler tesadüf blokları deneme desenine göre 7 tekerrürlü olarak kurulmuştur. Denemelerde bitki yetiştirme ortamı olarak kumlu toprak karışımı kullanılmış, 400 adet ikinci dönem larva dikimle birlikte bitkiye inokule edilmiştir. Bitki yetiştirmede $30 \mathrm{~mm}$ çapında, $115 \mathrm{~mm}$ yüksekliğinde, 80 gram toprak kapasiteli yuvarlak tüpler kullanılmıştır. Denemede, bitkiler 23-25 ${ }^{\circ} \mathrm{C}$ 'de 16 saat gün 1 şı ğ 1 altında 12 hafta boyunca yetiştirilmiştir (Şekil 1).

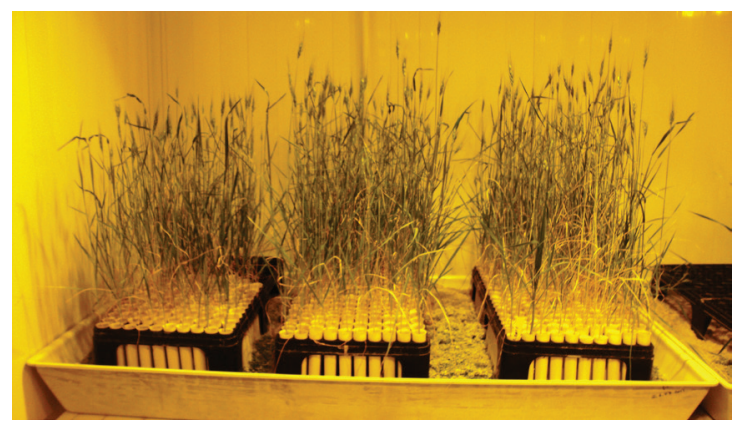

Şekil 1- Heterodera latipons'a karșı bazı buğday melezlerin reaksiyonlarının araştırılması

Figure 1-Investigation of the reactions of some wheat hybrids aganist Heterodera latipons

Deneme sonunda her bir tüpteki bitki kökleri ve toprakta bulunan kistler sayılmıştır. Buna göre her bir bitkide, 5 veya daha az kist: dayanıklı, 5-10 kist: orta dayanıkl1, 10-14 kist: orta hassas, 15-25 kist: hassas ve 25 veya üzeri kist: çok hassas olarak sınıflandırılmış (Nicol 2009) veriler SPSS 10.0 (SPSS Inc., Chicago, IL, USA) paket programı kullanılarak ANOVA testi ile değerlendirilmiştir. Kist oluşumu görülen her bitki ikinci kez denemeye alınarak sonuçlar teyit edilmiştir. 


\section{Bulgular ve Tartışma}

Çalışmada genomunda dayanıklılık geni taşıyan 38 çeşit ile dayanıklılık geni taşımayan 26 çeşit olmak üzere toplam makarnalık buğday 64 melezinin $H$. latipons' $a$ karşı dayanıklılıkları araştırılmış, 20 çeşit dayanıklı, 32 çeşit orta dayanıklı ve 12 çeşidin ise nematoda karşı orta hassas olduğu tespit edilmiştir. Çalışmada çok hassas ve hassas reaksiyon veren çeşide rastlanılmamıştır.

\subsection{Crel genine sahip melezlerin Heterodera latipons'a karşı reaksiyonları}

Çalı̧̧mada dayanıklılık geni Crel'e sahip 38 melez içerisinden 10 melezin nematoda karşı dayanıklı, 20 melezin orta dayanıklı, 8 melezin ise orta hassas olduğu tespit edilmiştir (Çizelge 1). Cre 1 genin $H$. latipons'a karşı mutlak bir dayanıklılık sağlamadığı ancak \% 78 dayanıklılık oranı ile oldukça başarılı olduğu saptanmıştır.

Heterodera latipons'a karşı dayanıklı olduğu saptanan $\mathrm{Cre} 1$ genine sahip melezlerin çoğunlukla SOKOLL, SILVERSTAR vePASTOR ebeveynlerine ait olduğu, söz konusu melezlerde kist oluşumunun 4 ve altında olduğu görülmektedir (Çizelge 1). Genomunda Cre 1 bulunduran ve nematoda karş1 orta dayanıklı olan 20 melezin SILVERSTAR, PASTOR ve CROC_1/AE.SQUARROSA(224)// OPATA melezleri olduğu görülmektedir (Çizelge 1).

Çalışmada 8 melezin dayanıklılık geni Crel'e sahip olmakla birlikte $H$. latipons'a karşı orta hassas olduğu tespit edilmiştir. Söz konusu melezlerin çoğunda kist sayısı "Orta Dayanıklı" grubun üst değeri olan 10 kiste yakın olduğu ve standart sapma değerleri dikkate alındığında melezlerin orta dayanıklı sınıfın içinde olabileceği görülmektedir. Bu durum Cre1 genin H. latipons'a karşı etkinliğinin çalışmada saptanan orandan daha yüksek olabileceğini işaret etmektedir (Çizelge 1).

\subsection{Crel geni taşımayan melezlerin Heterodera latipons'a karşı reaksiyonları}

Denemeye alınan çeşitler içerisinde genomunda dayanıklılık geni bulundurmamakla birlikte nematoda karşı dayanıklı ve orta dayanıklı olan
22 çeşit olduğu tespit edilmiştir. Bu çeşitlerin SILVERSTAR, CROC_1/AE.SQUARROSA(224)// OPATA, PASTOR ve SOKOLL ebeveynlerine ait melezler olduğu görülmektedir. Ayrıca, dayanıklılık genine sahip olmayan 4 çeşidin ise nematoda karşı orta hassas olduğu saptanmıştır (Çizelge 2).

Tahıl kist nematodu ile mücadelede dayanıklılık genlerinin nematodun türüne ve patotipine karş1 etkinliklerinin araştırılması ve söz konu genlerin 1slah programlarında kullanımına yönelik çalışmalar dünya genelinde oldukça yoğun bir şekilde yürütülmektedir. Ülkemizde de Tahıl kist nematodu popülasyonlarına karşı dayanıklılık kaynaklarının etkinliğinin belirlenmesi çalışmaları son yıllarda büyük bir ivme kazanmıştır. Akar ve ark (2009), Türkiye'de 200'ün üzerinde yerel çeşidin Cre 1 ve Cre 3 genleri yönünden taramasını yaptıkları çalışmada, ulusal çeşitlerde söz konusu genlere rastlanılmadığını bildirmektedir. Nicol ve ark (2009), Tahıl kist nematodu H. filipjevi' ye karşı dayanıklılık genleri CreR, Cre 1 ve Cre5' in orta düzeyde dayanıklı olduğu, Cre3 ve Cre8 hassas olduğunu, Şahin (2010) ise H. filipjevi'nin Haymana popülasyonuna karş1 HN7/OROFEN//BJN8/3/SERI82 pedigrili hat, Aegilops tauchii\#40, Aegilops speltoides aucheri, Triticum dicoccoides\#43, Triticum dicoccoides\#45, Aegilops vavilovi yabani buğday türlerinin dayanıklı olduğunu bildirmektedirler. Özarslandan ve ark (2010) ve Toktay et al (2012) dayanıklılık geni Crel'in Tahıl kist nematodu H. filipjevi'nin Haymana ve Yozgat popülasyonuna karşı hassas reaksiyon gösterdiğini bildirmişlerdir. İmren ve ark (2013) bazı dayanıklılık genlerinin etkinliklerinin Tahıl kist nematodu, $H$. avenae, $H$. filipjevi ve $H$. latipons'a göre değiştiği; bunla birlikte Crel'in her üç nematod popülasyonuna (Adana - $H$. avenae, Elbistan - H. filipjevi ve Kilis - H. latipons) orta dayanıklılığa sahip olduğu, $C r e 3$ ve Cre7'nin $H$. avenae ve $H$. latipons'a, CreR'nin $H$. filipjevi ve $H$. latipons'a, Cre8'in ise sadece $H$. filipjevi popülasyonuna karşı orta dayanıklı olduğu ve Cre2'nin ise her üç nematod türüne karşıda hassas olduğunu saptamışlardır.

Yukarıdaki çalışmalar ışığı altında dayanıklılık geni Crel'in ülkemizdeki Tahıl kist nematodu 
Çizelge 1- Cre1 genine sahip melezlerin Heterodera latipons'a karşıı reaksiyonları

Table 1-Reactions of some wheat hybrids having Crel gene aganist Heterodera latipons

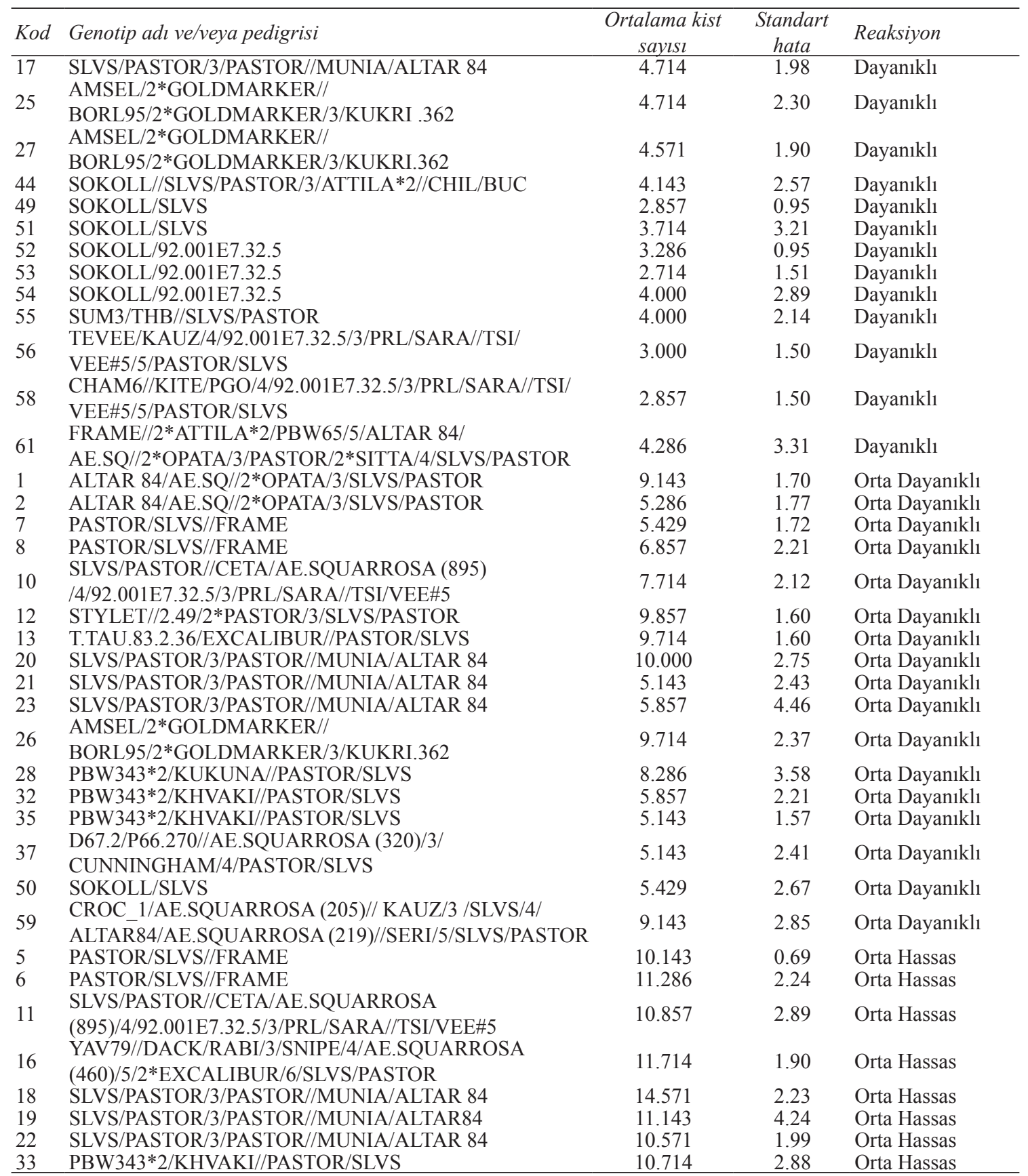

*, 5 veya daha az kist ve dayanıklı; 5-10 kist ve orta dayanıklı; 10-14 kist ve orta hassas; 15-25 kist ve hassas; 25 veya üzeri kist ve çok hassas 
Çizelge 2- Cre1 geni taşımayan melezlerin Heterodera latipons'a karşı reaksiyonları

Table 2-Reactions of some wheat hybrids lacking Crel gene aganist Heterodera latipons

\begin{tabular}{|c|c|c|c|c|}
\hline Kod & Genotip adl ve/veya pedigrisi & $\begin{array}{l}\text { Ortalama } \\
\text { kists saylsl }\end{array}$ & $\begin{array}{l}\text { Standart } \\
\text { hata }\end{array}$ & Reaksiyon \\
\hline 9 & $\begin{array}{l}\text { SLVS/PASTOR//CETA/AE.SQUARROSA } \\
(895) / 4 / 92.001 E 7.32 .5 / 3 / \text { PRL/SARA//TSI/VEE\#5 }\end{array}$ & 4.00 & 1.72 & Dayanıklı \\
\hline 15 & $\begin{array}{l}\text { YAV79//DACK/RABI/3/SNIPE/4/AE.SQUARROSA } \\
(460) / 5 / 2 * \text { EXCALIBUR/6/SLVS/PASTOR }\end{array}$ & 4.14 & 1.29 & Dayanıklı \\
\hline 36 & PBW343*2/KHVAKI//PASTOR/SLVS & 3.86 & 2.23 & Dayanıklı \\
\hline 38 & CALINGIRİ/SOKOLL & 4.14 & 1.62 & Dayanıklı \\
\hline 39 & STYLET//2.49/2*PASTOR & 3.86 & 1.72 & Dayanıklı \\
\hline 40 & ALTAR84/AE.SQ//2*OPATA/3/EXCALIBUR/4/SLVS/PASTOR & 4.00 & 2.94 & Dayanıklı \\
\hline 47 & SOKOLL/FRAME & 3.57 & 2.41 & Dayanıklı \\
\hline 57 & $\begin{array}{l}\text { TEVEE/KAUZ/4/92.001E7.32.5/3/PRL/SARA//TSI/VEE\#5/5/ } \\
\text { PASTOR/SLVS }\end{array}$ & 4.43 & 2.36 & Dayanıklı \\
\hline 60 & PBW343*2/KUKUNA*2//PASTOR/SLVS & 2.71 & 1.38 & Dayanıklı \\
\hline 63 & $\begin{array}{l}\text { KRİCHAUFF/FINSI/3/URES/PRL//BAV92/4/ALTAR84/ } \\
\text { AE.SQ//2*OPATA/3/SLVS/PASTOR }\end{array}$ & 12.14 & 4.28 & Dayanıklı \\
\hline 3 & ALTAR 84/AE.SQ//2*OPATA/3/SLVS/PASTOR & 6.14 & 1.38 & Orta Dayanıklı \\
\hline 29 & PBW343*2/KUKUNA//PASTOR/SLVS & 6.57 & 0.98 & Orta Dayanıklı \\
\hline 30 & PBW343*2/KUKUNA//PASTOR/SLVS & 6.43 & 3.80 & Orta Dayanıklı \\
\hline 31 & PBW343*2/KUKUNA//PASTOR/SLVS & 7.86 & 3.83 & Orta Dayanıklı \\
\hline 34 & PBW343*2/KHVAKI//PASTOR/SLVS & 5.43 & 2.41 & Orta Dayanıklı \\
\hline 41 & ALTAR84/AE.SQ//2*OPATA/3/EXCALIBUR/4/SLVS/PASTOR & 7.00 & 2.79 & Orta Dayanıklı \\
\hline 42 & ALTAR84/AE.SQ//2*OPATA/3/EXCALIBUR/4/SLVS/PASTOR & 8.57 & 3.85 & Orta Dayanıklı \\
\hline 45 & SOKOLL//SLVS/PASTOR/3/ATTILA*2//CHIL/BUC & 5.71 & 1.38 & Orta Dayanıklı \\
\hline 46 & SOKOLL/FRAME & 5.71 & 3.10 & Orta Dayanıklı \\
\hline 48 & SOKOLL/FRAME & 8.14 & 2.94 & Orta Dayanıklı \\
\hline 62 & $\begin{array}{l}\text { FRAME//2*ATTILA*2/PBW65/5/ALTAR 84/AE.SQ//2*OPATA/3/ } \\
\text { PASTOR/2*SITTA/4/SLVS/PASTOR }\end{array}$ & 5.43 & 2.43 & Orta Dayanıklı \\
\hline 64 & $\begin{array}{l}\text { KRİCHAUFF/FINSI/3/URES/PRL//BAV92/4/ALTAR 84/ } \\
\text { AE.SQ//2*OPATA/3/SLVS/PASTOR }\end{array}$ & 9.29 & 1.57 & Orta Dayanıklı \\
\hline 4 & ALTAR 84/AE.SQ//2*OPATA/3/SLVS/PASTOR & 14.00 & 4.60 & Orta Hassas \\
\hline 14 & $\begin{array}{l}\text { CROC_1/AE.SQUARROSA (224)//OPATA/3/RAC655/4/SLVS/ } \\
\text { PASTOR }\end{array}$ & 10.29 & 2.12 & Orta Hassas \\
\hline 24 & SLVS/PASTOR/3/PASTOR//MUNIA/ALTAR 84 & 10.57 & 1.50 & Orta Hassas \\
\hline 43 & SOKOLL//SLVS/PASTOR/3/ATTILA*2//CHIL/BUC & 10.14 & 2.54 & Orta Hassas \\
\hline
\end{tabular}

* 5 veya daha az kist: dayanıklı, 5-10 kist: orta dayanıklı, 10-14 kist: orta hassas, 15-25 kist: hassas ve 25 veya üzeri kist: çok hassas

türlerine ve patotiplerine karşı etkinliklerinin farklı olduğu genelde nematoda karşı yüksek bir etkinliğe sahip olduğu anlaşılmaktadır. $\mathrm{Bu}$ bağlamda çalışmada etkinliği araştırılan dayanıklılık geni Cre1'in H. latipons'un Gaziantep (Karkamış) popülasyonuna karş1 \% 78 ile yüksek derece bir dayanıklılığa sahip olduğu saptanmış olup, çalışma bulgularının ülkemizde yapılan önceki araştırma sonuçları ile örtüştüğü tespit edilmiştir. 


\section{Sonuçlar}

Dünyada buğdayın ana zararlıları içerisinde yer alan Tahıl kist nematodu (Heterodera avenae group) mücadelesinde dayanıklılık kaynaklarının (Cre genleri) kullanımı ve nematoda karşı dayanıklı/tolerant çeşit geliştirilmesi en önemli mücadele yöntemi olarak bilinmektedir. $\mathrm{Bu}$ çalışmada söz konusu dayanıklılık genlerinden Cre1'in \% 78 etkinlik oranı ile H. latipons'un Gaziantep (Karkamış) popülasyonuna karşı etkili olduğu belirlenmiştir. Ayrıca, denemeye alınan SILVERSTAR, SOKOLL, CROC_1/ AE.SQUARROSA(224)//OPATA ve PASTÖR melezlerinin nematoda karşı etkin olduğu saptanmıştır. Bu bağlamda ulusal buğday islah programlarında Tahıl Kist nematodu H. latipons'a karşı dayanıklılık geni Cre1'in kullanılabileceği sonucuna varılmıştır.

\section{Teşekkür}

$\mathrm{Bu}$ çalışma kullanılan buğday melezleri Uluslararası Misır ve Buğday Geliştirme Merkezi (CIMMYT)'in Meksika'daki Buğday Islah Programı'ndan temin edilmiş olup, adı geçen kurum ve programa teşekkürlerimi sunarım.

\section{Kaynaklar}

Agrios G N (1997). Plant Pathology, fourth edition. Academic Press Inc., London

Akar T, Calıskan M, Nicol J M, Uranbey S, Sahin E, Yazar S, William M \& Braun H J (2009). Molecular characterization of Cereal Cyst Nematode diagnostic markers $\mathrm{Cre} 1$ and $\mathrm{Cre} 3$ in some winter wheat germplasm and their potential use against Heterodera filipjevi, Field Crops Research 114(2): 320-323

Barloy D, Lemoine J, Abelard P, Tanguy A M, Rivoal R \& Jahier J (2007). Marker-assisted Pyramiding of Two Cereal Cyst Nematode Resistance Genes From Aegilops variabilis in Wheat. Molecular Breeding 20: 31-40

Bekal S, Jahier J \& Rivoal R (1998). Host response of different Triticeae to species of the cereal cyst nematode complex in relation to breeding resistant durum wheat. Fundamental Applied Nematology 21: $359-370$
Boerma H R \& Hussey R S (1992). Breeding Plants for Resistance to Nematodes. Journal of Nematology 24(2): 242-252

Cook R \& Rivoal R (1998). Genetics of resistance and parasitism. In: Sharma, S. B. (Ed.). The Cyst Nematodes. Chapman and Hall, London

Cook R \& Noel G R (2002). Cyst nematodes: Globodera and Heterodera Species, In: Plant Resistance to Parasitic Nematodes (Eds. Star J L, Cook R \& Bridge J.), CAB International, pp. $71-105$

İmren $\mathrm{M}$, Toktay $\mathrm{H}$, Özarslandan $\mathrm{A}$, Nicol $\mathrm{J} \mathrm{M}$ \& Elekcioğlu I H (2012). Güneydoğu Anadolu Bölgesi tahil alanlarında Tahil kist nematodu, Heterodera avenae group türlerinin belirlenmesi. Türkiye Entomoloji Dergisi 36(2): 265-275

İmren M, Toktay H, Bozbuğa R, Erginbaş Orakçı G, Dababat A \& Elekcioğlu İ H (2013). Identification of genetic resistance to cereal cyst nematodes; Heterodera avenae (Wollenweber, 1924), H. filipjevi (Madzhidov, 1981) Stelter and H. latipons (Franklin, 1969) in some international bread wheat germplasms. Turkish Journal of Entomology 37(3): 277-282

Kort J (1972). Nematode diseases of cereals of temperate climates, In: Webster, J. M. (Ed.). Economic Nematology. Academic Press, New York, 97-126

Majnik J, Ogbonnaya F C, Moullet O \& Lagudah E S (2003). The Crel and Cre3 Nematode Resistance Genes are Located at Homeologous Loci in the Wheat Genome. The American Phytapathological Society. MPMI 16(12): 1135-1144

Nicol J M, Rivoal R, Bolat N, Aktas H, Braun H J, Mergoum M, Yıldırım A F, Bağcı A, Elekcioğlu I H \& Yahyaoui A (2002a) The frequency and diversity of the cyst and lesion nematodes on wheat in the Turkish Central Anatolian Plateau. Nematology 4(2): 272

Nicol, J M (2002b). Important nematode pests. In: Curtis, B. C., Rajaram, S., Gomez Macpherson. H. (Eds.). Bread Whead Improvement and Production. Food and Agriculture Organization of the United Nations, Rome, 345-366

Nicol J. M (2009). Occurrence of Cereal Cyst Nematode, Heterodera avenae, in Southeast Anatolia, Turkey, Proceedings of the First Workshop of the International Cereal Cyst Nematode Initiative, Antalya, Turkey, pp. 10-11

Özarslandan M, Özarslandan A, Nicol J M \& Elekcioğlu İ H (2010). Tahil kist nematodu, Heterodera filipjevi (Madzhidov, 1981) Stelter'nin patotipinin 
belirlenmesi ve buğday genotiplerinin, H. filipjevi populasyonlarına karşı dayanıklılıklarının araştırılması. Türkiye Entomoloji dergisi 34(4): 515527

Rivoal R \& Cook R (1993). Nematode Pests of Cereals, Plant Parasitic Nematodes in Temperate Agriculture,ed: Evans K, Trudgill D L, Webster J M, $\mathrm{CAB}$ International: Wallingford, United Kingdom, $\mathrm{p}$. 259-303

Rivoal R, Bekal S, Valette S, Gauthier J P, Bel Hadj Fradj M, Mokabli A, Jahier J, Nicol J M \& Yahyaoui A (2001). Variation in reproductive capacity and virulence on different genotypes and resistance genes of Triticeae, in the cereal cyst nematode species complex. Nematology 3(6): 581 - 592

Rumpenhorst H J, Elekcioğlu I H, Sturhan D, Öztürk $\mathrm{G}$ and Enneli S (1996). The Cereal Cyst Nematode Heterodera filipjevi (Madzhidov) in Turkey. Nematologia Mediterranea 24: 135- 138

Sasser J N A (1987). Perspective on Nematode Problems Worldwide, Ed: Saxena, M.C., Sikora, R.A., Sarivastava, J.P., Nematode Parasitic to Cereals and Legumes in Temperate Semi-Arid Regions Proceedings of a Workshop Held at Larnaca, Cyprus, pp. 1-12

Schmidt A L, Mcintyre C L, Thompson J, Seymour N P \& Liu C J (2005). Quantitative trait loci for root lesion nematode (Pratylenchus thornei) resistance in Middle-Eastern landraces and their potential for introgression into Australian bread wheat. Australian Journal of Agricultural Research 56: 1059-1068

Scholz U \& Sikora R (2004). Hatching behaviour and life cycle of Heterodera latipons Franklin under Syrian
Agro - Ecological Conditions. Nematology 6(2): 245 $-256$

Shepherd A M (1986). Extraction and Estimation of Cyst Nematodes, ed: Southey J.F., Laboratory Methods for Work with Plant and Soil Nematodes, London, Her Majesty's Stationary Office, pp: 51-58

Slootmaker L, Lange G, Jochemsen G \& Schepers J (1974). Monosomic Analysis in Bread Wheat of Resistance to Cereal Root Eelworm. Euphytica 23: 497-503

Subbotin S A, Sturhan D, Rumpenhorst H J \& Moens M (2003). Molecular and morphological characterisation of the Heterodera avenae species complex (Tylenchida: Heteroderidae). Nematology 5: 515-538

Subbotin S A, Mundo-Ocampo M \& Baldwin J G (2010). Systematics of Cyst Nematodes (Nematode: Heteroderinae) Nematology monographs and Perspectives 8A. In: Biology and Evolution. Brill Leiden-Boston, pp.68

Şahin E (2010). Orta Anadolu Buğday Alanlarında Önemli Bitki Paraziti Nematodların Belirlenmesi ve Tahıl Kist Nematoda Heterodera filipjevi nin Biyolojisi ile Mücadelesi Üzerine Çalışmalar. Çukurova Üniversitesi Fen Bilimleri Enstitüsü, Doktora tezi (Basılmamış), Adana

Toktay H, Yavuzaslanoğlu E, İmren M, Nicol J M, Elekcioğlu I H \& Dababat A (2012). Screening for resistance to Heterodera filipjevi and Pratylenchus thornei in sister lines of spring wheat. Turkish Journal of Entomology 36(4):455-461

Tuik (2012). Türkiye İstatistik Kurumu, Bitkisel Üretim İstatistikleri (www.tuik.gov.tr) (Erişim tarihi: Kasım, 2013) 